\title{
Research on Structuring Model of Information Service System for "Smart Urban Agglomeration" of Changsha-Zhuzhou-Xiangtan Based on Big Data Requirements
}

\author{
Xin Liu ${ }^{*}$ \\ Hunan Railway Professional Technology College, Zhuzhou, Hunan, 412001, China
}

\begin{abstract}
Accompanied by the deep development of big data technologies in urbanization, the smart city, which is supported by big data technologies, has revealed its potential gradually. As the core content of smart city, the smart information service becomes a frequent subject and direction of related researches. This paper will firstly investigate the information service demand of various groups of people in "Smart Urban Agglomeration" of Changsha-Zhuzhou-Xiangtan. Then, based on above the investigation, aiming to provide valuable suggestions on promoting the construction of smart city and the transformation of information service, this paper proposes functions of information service of "Smart Urban Agglomeration" of Changsha-Zhuzhou-Xiangtan, and structures the model of the information service system for "Smart Urban Agglomeration" of Changsha-Zhuzhou-Xiangtan.
\end{abstract}

Keywords: Big data, functions design for information service, model structuring for service system, smart city.

\section{INTRODUCTION}

The development of smart city with big data technologies is a complex systematic project, which is also subject to the development level of the society and economy. By using the new generation of information technologies such as IoT, cloud, decision-making analysis and optimization, with perceptive, networked and smart methods, this paper proposes to create an entity of urban information service system with new big data technologies, which can remove barriers on the way to smart city, realize vast and sufficient sharing and linking of general information among resources in the city, as well as perceive, integrate, analyze and respond that information smartly, thus to provide dynamic control capacity and decision-making support in the development and operation of city, speed up the transformation of government to service type, facilitate the upgrading of regional industrial economy, and improve the living standard of people. This is an important strategic measure for every city [1].

\section{NEW CHANGES OF DEMAND ON INFORMATION SERVICE OF "SMART CITY"IN BIG DATA RE- QUIREMENTS}

The various changes of information demand in big data requirements are derived from different conditions within government, corporations, organizations, groups and personals in the city, which is an inevitable event in "Smart City" originated from a society with highly developed information and smart technologies. For introducing "Smart City" information service system, it is mandatory to start with analysis with big data technologies on the changes of social information demand in "Smart City". Generally speaking, the major new changes of demand are as below $[2,3]$ :

*Address correspondence to this author at the Hunan Railway Professional Technology College, Zhuzhou, Hunan, 412001, China; Tel: 13973376277; E-mail: 57112575@qq.com

\subsection{More Specialized}

The social information services in "Smart City" are different from each other for different groups of people, and become more and more diversified, which is because the information service demands of people are not limited only in fields of hi-tech and high speed running economy, but also spread to various aspects in the society such as production, living, learning and social activities, which indicates the comprehensive improvement of living standard regarding the information quality of the whole society. Therefore, in the situations requiring highly developed big data technologies, the different groups of people are stimulated continuously for more and more specialized information demands.

\subsection{More Time-Sensitive}

People expect immediate, corresponding and accurate information service to satisfy their instant information demand, which is a common characteristic of the time-sensitivity of information service. On one and, higher standard of the information service is required by people in social activities for timely response to meet the standard of fast-paced living. On the other hand, the fast-paced social environment determines that the urban information resources and products have inborn advantage of shorter responding time, but which is still behind the expectation of people. In consequence, the information service of smart city with big data technologies is granted with more and higher requirements and expectations.

\subsection{Smarter}

Accompanied by the development of big data technologies, people are not only in search for acquiring information, but also for intelligent decision-making after collecting and analyzing the information. This is to pursue highly intelligent informative outcome, which is generated by high level 
of information demand. It is a combination of more developed informatization and intelligentization, which are composed of highly developed social information infrastructure, widespread and fluent information transmit channel, and a general higher level of information attainment of members of the society, rather than recognizing the traditional massive information resources, or an alternate approach required by people when there is lack of information resources.

\subsection{More Flexible}

The provider of social information service should be able to deliver their information services through various channels, platforms and formats to people, regardless of when and/or where and/or how the situation they are. The vaster space for informative activities is an important evolution of information service into ubiquitous and socialized big data requirements, which require the provider of information service in smart city to use more flexible methods, paths and nodes.

\section{DEMAND ANALYSIS OF INFORMATION SER- VICE OF "SMART URBAN AGGLOMERATION" OF CHANGSHA-ZHUZHOU-XIANGTAN IN BIG DATA REQUIREMENTS}

This paper conducts detailed analysis on the information service demand in several aspects such as public service, livelihood application, economy mode, based on the status derived from new changes of information demand of "Smart City" in the big data requirements [4-6].

\subsection{Analysis from Public Service Angle}

\subsubsection{Construction Plan and Management System}

By analyzing the valid questionnaires with big data technologies, this paper finds that what is needed most by the people of Changsha-Zhuzhou-Xiangtan urban agglomeration is smart government, which implies that the urban citizens pay more attention to the government reform and public services. Following are current tasks of the government to work on and those that will be effective: 1) reform government offered public service, and make appropriate adjustment to policies to adapt "Smart Urban Agglomeration", as well as promote the construction of smart city by guiding the actions of government agencies; 2) make development plan and related supporting policy, supervision and legislation to realize data sharing, improve the management level of information, assure the safety of private data, and protect information management mechanism; 3) realize coordinate services among communication, data, information and application to facilitate the formation of uniform standards of industries jointly made by the practitioners and so on.

Regarding the construction of smart government, as shown in the big data, two functions are valued mostly by the people which are the e-supervision for the whole process of governmental acts and the interaction between the people and government, weighing $25 \%$ and $23 \%$ respectively, as shown as in Fig. (1). Therefore, bringing the governmental information into public should be the key point of construction of "Smart Urban Agglomeration" of ChangshaZhuzhou-Xiangtan. Furthermore, the people should be encouraged to take a part in the construction of smart electronic government by providing suggestions and advice via various channels.

\subsubsection{Talents Training and Environment Cultivation}

The people of Changsha-Zhuzhou-Xiangtan urban agglomeration demand high level of smart education. Of course, the provincial government of Hunan also pays attention to education cause. The informatization of education is forming after years of development. For example, the "World University City" is a super large database with regional education and teaching characteristics, which integrated existing quality education resources home and abroad, as well as positively develop independently innovate and carry forward local resource advantages. The "Campus Network" project among Changsha, Zhuzhou and Xiangtan is for building a multi-media remote education network system which has regional characteristics, reasonable structure and high-speed network. The universities are turning to new techniques gradually, such as all-dimensional virtual environment, teaching games and teaching Apps to improve the experience of students.

By analyzing the valid questionnaires with big data technologies, this paper highlights that the people of ChangshaZhuzhou-Xiangtan urban agglomeration are interested in smart remote library and network teaching, accounting to $35 \%$ and $34 \%$ respectively, as shown in Fig. (2). Therefore, it is necessary to establish search engine system through Internet to connect organizations such as top universities home and abroad, foreign science and technology websites. It will

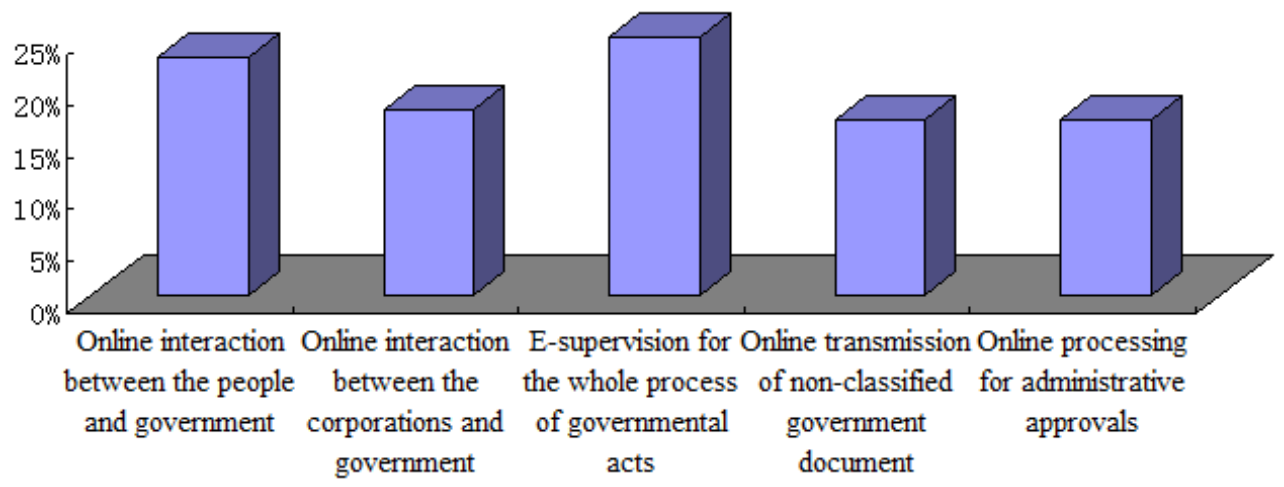

Fig. (1). Functions demand of smart government. 


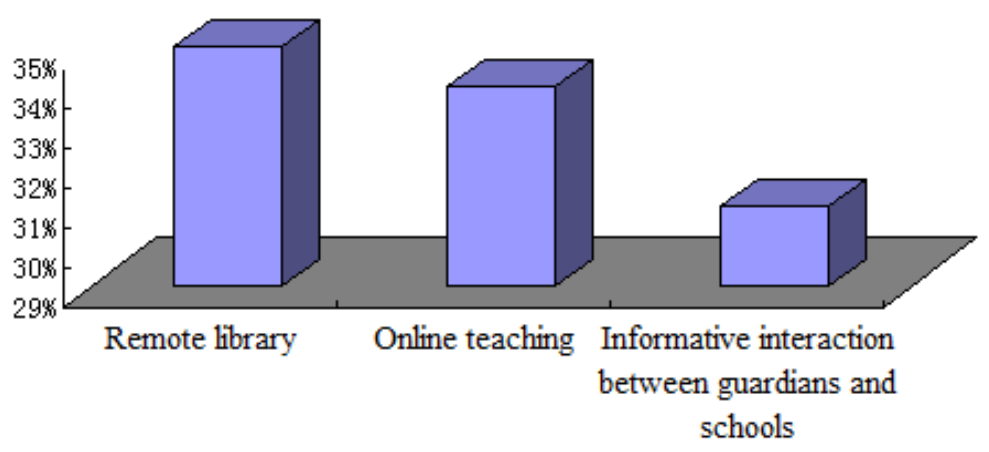

Fig. (2). Functions demand of smart government.

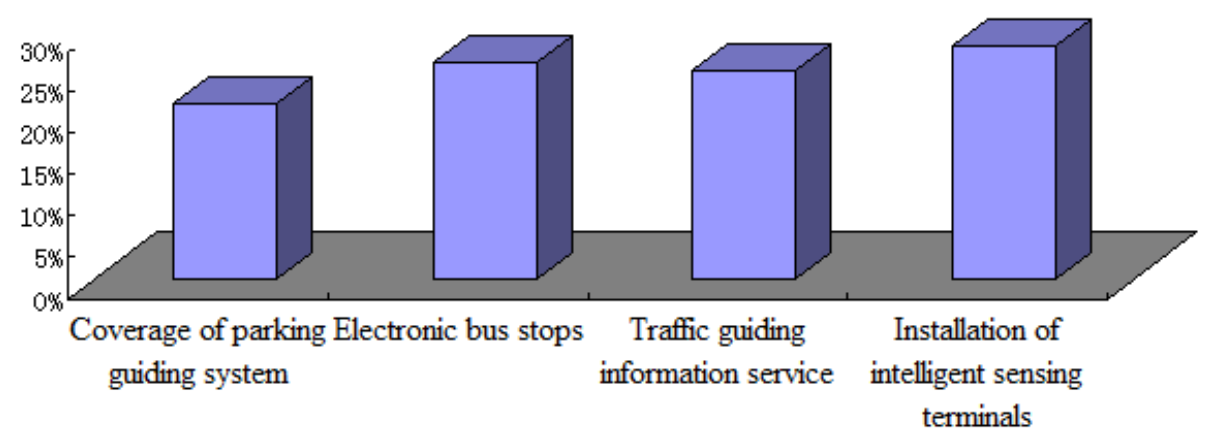

Fig. (3). Functions demand of smart traffic.

provide digital library, voice and visual resources system, digital archives, as well as valuable literature of natural and social sciences, and realize interactive learning.

\subsubsection{Traffic System Management and Optimization}

The people in Changsha-Zhuzhou-Xiangtan urban agglomeration are eager for smart traffic. Though the vehicles inventory in Changsha, Zhuzhou and Xiangtan is far behind that in Beijing or Shanghai, the traffic pressure is great as well, which keeps traffic jams, emergency lanes and parking space occupied, hampering trips and restricting policeman from reaching their duty location. Therefore, the construction of smart traffic is also expected. By analyzing the valid questionnaires with big data technologies, the traffic guidance informative service and installation of intelligent sensing terminals are highly expected, being $25 \%$ and $28 \%$ respectively, as shown in Fig. (3). People seek to know the comprehensive traffic information such as the bus, taxi, parking, road condition, etc, with one single platform to timely, correctly and reliably schedule their trips. This can fix the "Urban Diseases" of every big city, relieve the traffic jamming and reduce the traffic cost.

There should be high efficient urban traffic operation system in Changsha-Zhuzhou-Xiangtan urban agglomeration, for example, developing a smart management system in which the public traffic means are with high priorities, optimizing the technologies for uniform entity of urban rail traffic and new model of traffic system, coordination technologies for emergency treatment and accident prevention and early warning in urban traffic, technologies for combining maintenance and jam diversion for urban roads, sharing technologies for comprehensive traffic and information resources, etc.

\subsection{Analysis from Livelihood Application Angle}

\subsubsection{Construction and Application of Intelligent Medical Treatment}

Medical treatment attracts the most attention from the public. It is an area associated mostly with the people's livelihood, in terms of practicability and having high market demand. People in Changsha, Zhuzhou and Xiangtan cities are quite concerned about and have great demand for intelligent medical treatment, which requires these cities to apply, at a fast pace, cloud computing, internet of things (IOT), mobile internet and other advanced technology into medical treatment. This is to drive integration with technology and then drive the use of limited resources with integration for the well-being of more people and to allow more people to have access to diversified medical services and medical treatments, fully manifesting the effects of intelligent medical treatment. According to big-data application analysis on valid questionnaires, Electronic Health Record and Electronic Medical Record account for $37 \%$ and $34 \%$ of all health and medical records, respectively, as shown in Fig. (4) below:

The people in Changsha, Zhuzhou and Xiangtan may expect in future for real-time control of the treatment on patients through intelligent medical curing, and file the electronic health record and electronic medical history via backend database. Therefore, for intelligent medical treatment with IoT, by collecting medical and physical parameters of people, and by analyzing their status, there should be remote medical treatment service, which enables the participation of the community and separated family members for a better earlier diagnosis in the urban agglomeration of ChangshaZhuzhou-Xiangtan. 


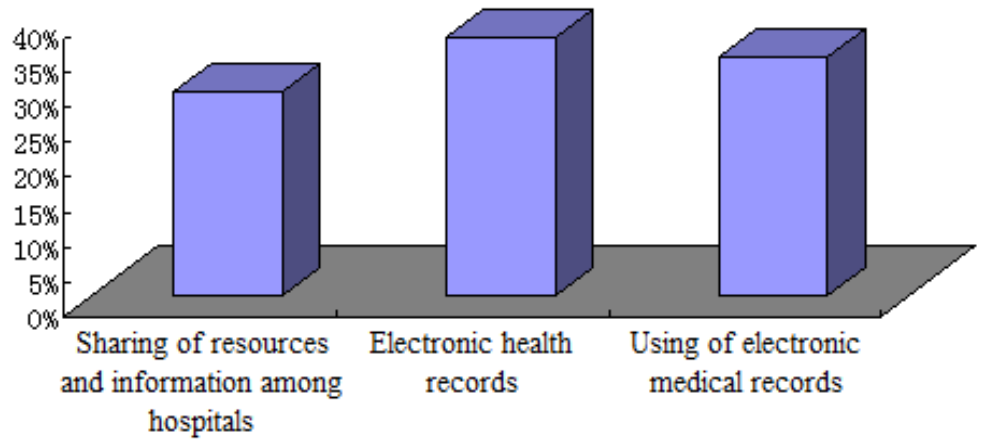

Fig. (4). Functions demand of smart medical.

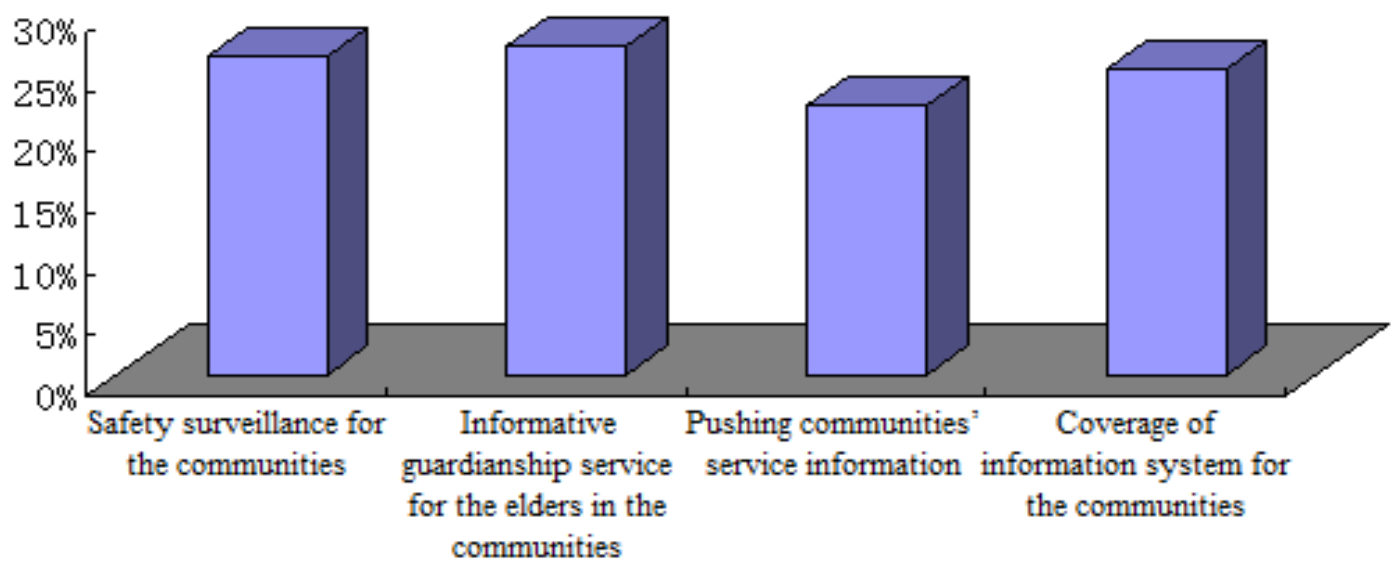

Fig. (5). Functions demand of smart community.

\subsubsection{Construction and Application of Smart Community}

During the city construction in Changsha, Zhuzhou and Xiangtan, due to uncertain networked management partition and unsound equipment deployment, the lack of information infrastructure delays the construction of smart community. Furthermore, because most of the people are not clearly aware of the concept of smart community, their demands for smart community are not inspired, especially the elders in the old communities. However, smart community is a must for the construction of smart city, providing deep social service, convenient mutual service between people, and n sound public service foundation. In this way, people will receive assurance for the safety of their houses, and awareness of convenient services which could be obtained without going out, such as paying the bills of water and electricity, emergency medial curing, medical appointment, and home-based care for the aged.

By analyzing the valid questionnaires with big data technologies, the people in Changsha, Zhuzhou and Xiangtan are inclined towards the informationized guardianship for the elders and the house safety in the communities, weighing $27 \%$ and $26 \%$ respectively, as shown in Fig. (5). Therefore, the urban agglomeration of Changsha-Zhuzhou-Xiangtan collects data with GIS, as well as treats and analyzes the data from smart center to complete projects such as community camera surveillance, community management and services, and realize the spatial, elaborate and visual layout management for treatments of community events.

\subsection{Analysis from Economy Mode Angle}

\subsubsection{Construction and Application of Intelligent Medical Security}

Recent years have witnessed frequent earthquakes, tsunamis, fires and other disasters, and frequent occurrence of quality problems concerning foods and drugs, which has severely slackened the pace of industrial development and constrained the economic development of certain regions, areas and even specific industries. This situation has imposed a sense of depression on people's inner peace of mind. They are eager to have emergency precautions against disasters and major incidents to avoid heavy prices. In particular, with regard to major emergencies, people hope that fullcoverage investigations can be carried out on emergencies so as to make them well aware of the reasons and true nature of those emergencies.

The big-data application analysis on valid questionnaires shows that citizens have greater demand for warnings and measures against natural disasters and major emergencies which account for $21 \%$ and $20 \%$ of the demand of all kinds of intelligent security, as shown in Fig. (6) below. This situation, on one hand, requires Changsha, Zhuzhou and Xiangtan cities to do well in intelligent protective measures and intelligent warning systems for disaster-prone areas and to take the disaster range under control in time so as to avoid largearea property losses. On the other hand, governments in Changsha, Zhuzhou and Xiangtan cities are required to establish intelligent emergency treatment platform against 


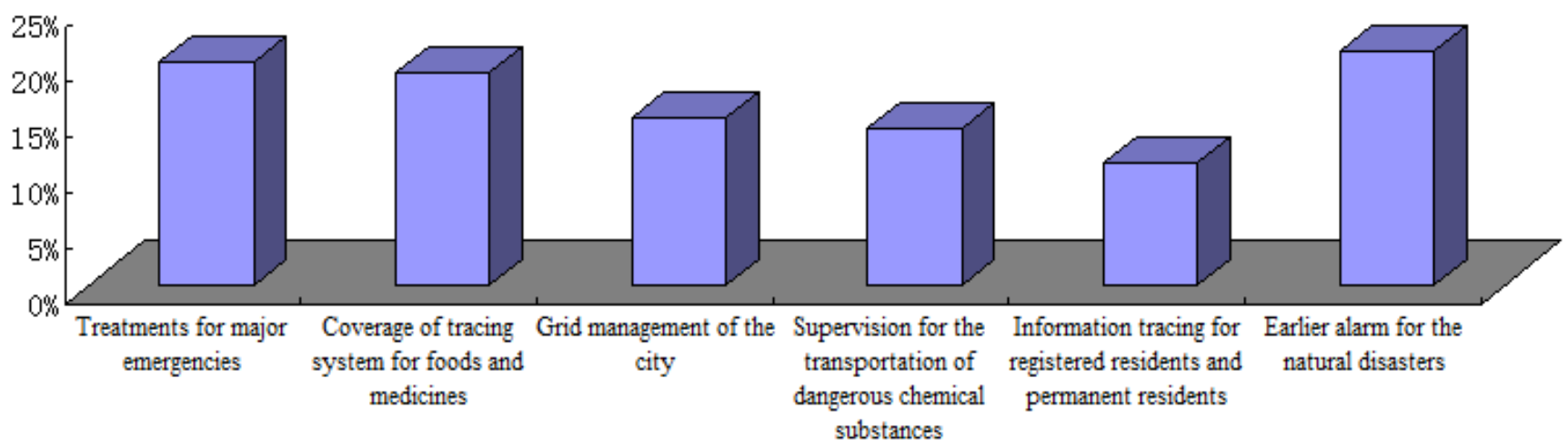

Fig. (6). Functions demand of smart safety.

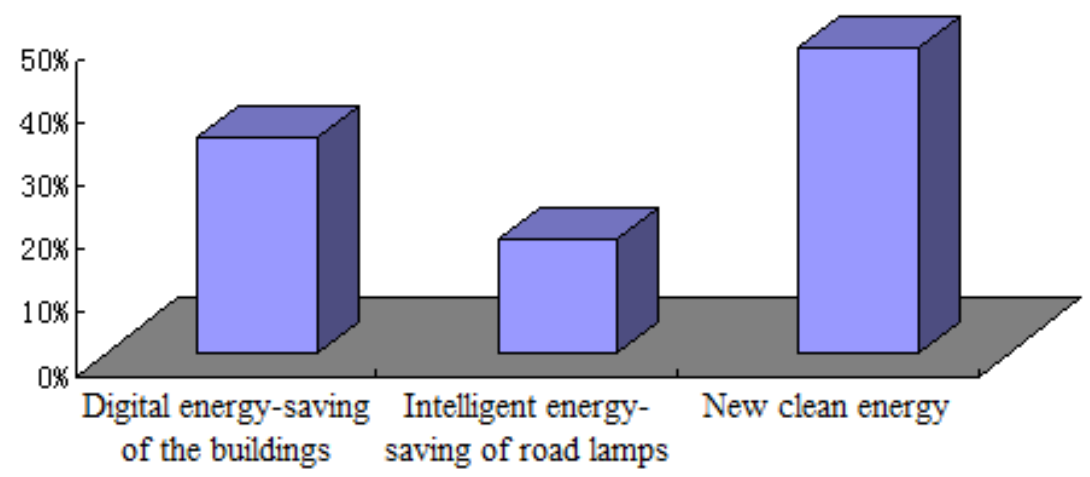

Fig. (7). Functions demand of smart energy.

major incidents so as to strengthen an overall intelligent management of staff, equipment and pre-arranged plans.

\subsubsection{Smart Energy Construction and Environment Im- provement}

The "Smart Urban Agglomeration" of ChangshaZhuzhou-Xiangtan should treat water and air environment, and comprehensively treat the degraded ecosystem and wetlands ecosystem with the support of environment-improving science and technique powers. Itis the only way of energy production for the "Smart Urban Agglomeration" of Changsha-Zhuzhou-Xiangtan that greatly improves the yield of resources, promoting the development of recycling economy and speeding up the establishment of the resources recycling system, which covers every link such as production, circulation and consumption in urban agglomeration with corporations and various levels of the society being major participants. The most valued aspect in smart energy in Changsha, Zhuzhou and Xiangtan is new clean energy, which accounts for $48 \%$, as shown in Fig. (7).

By analyzing valid questionnaires on big data technologies, the demands of the people in Changsha, Zhuzhou and Xiangtan reflect the improvement of the living standard. The government should directly support the research and development of smart energy technologies, which protect the environment and reduce carbon emission. The government should also promote the investment and development of the corporations in smart energy field by adjusting the tax policies related to energy corporations [7].

\section{FUNCTIONS DESIGN OF INFORMATION SER- VICE OF "SMART URBAN AGGLOMERATION" OF CHANGSHA-ZHUZHOU-XIANGTAN IN BIG DATA REQUIREMENTS}

Facing the improving overall perception of the city, the "Smart Urban Agglomeration" of Changsha-ZhuzhouXiangtan should respond intelligently for various aspects of the urban life, and provide the people with intelligent service in government affairs, business, environment, livelihood and public safety by intelligent information treatment and analysis. From the demand analysis based on big data, the information service of the "Smart Urban Agglomeration" of Changsha-Zhuzhou-Xiangtan is composed of 3 major fields, which are public management of smart government affairs, industrial transformation of smart business and social service of smart living. The detailed functions system of each field is shown in Fig. (8). [8-10].

\subsection{Smart Living}

For improving living standard, the smart city must provide the fundamental smart services to improve the social and living conditions and improve social advancement, thus to develop urban economy, perfect urban infrastructure, and realize the progress of science and technology.

\subsubsection{Smart Medical Treatment}

Medical treatment service is an important embodiment for the society that optimizes the medical resources, facilitating the uniformity and exchange of information systems 


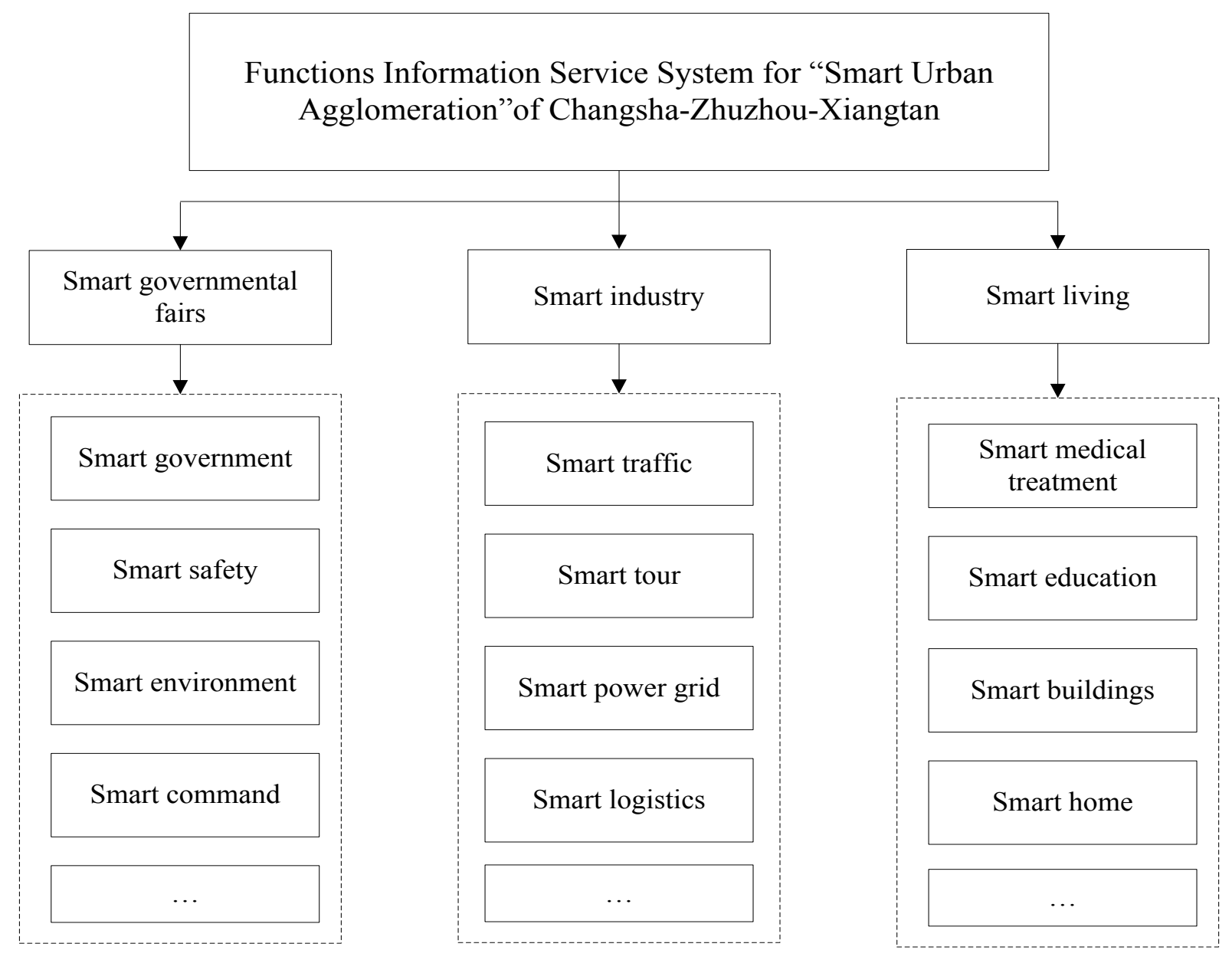

Fig. (8). Functions demand of smart energy.

among medical units, and realizing the communication and understanding between doctors and patients. Smart medical treatment and sanitation system are synchronous with the pace of the construction and development of smart city, which will be realized step by step. By structuring remote platform for medical service, health management platform for personnel, and real-time platform for curing and diseases control, full range of services for people could be achieved, for example, diseases prevention, diet adjustment, diseases diagnosis, etc, which will offer smart level of social medical and sanitation services with advanced smarter technologies. Therefore, it is very necessary to establish a smart medical treatment function system.

\subsubsection{Smart Education}

The effective development of a learning society is derived from smart information systematic platform for education such as grid sharing education resource database, virtual model of library, remote education platform, etc. Furthermore, it is also derived from the construction of smart education system. As it can provide fair opportunity to all the citizens in the society to accomplish their education, as well as improve the sharing of resources and facilitate the perfection of public service system for culture and information, establishing a smart education function system is extremely necessary.

\subsubsection{Intelligent Architecture}

A realization of intelligent communication and interaction between people and architecture is always an important objective for architecture intelligence, and the application of various intelligent technology, information technology and communication technology is the answer for such objective. This kind of intelligent architecture is a perfect combination of intelligent architecture technology and emerging information technology which can bring people a more comfortable, more convenient, more humanized and safer life. From this point of perspective, the construction of a function system of intelligent architecture is extremely essential.

\subsubsection{Smart Home}

Aiming to build a comfortable home, with sound design for wiring, communication, smart system and safety system, an accurate and perfect control platform and the like could be formed. To integrate all the equipment related to home and living is the so -called "Smart Home", which is a popular concept in foreign countries, also called as "Intelligent Home". For improving the safety, convenience, comfort, artistry of home, and having the whole living environment in ecological-balance, natural, environment-friendly and energy-saving status, it is a necessity to establish a smart home function system. 


\subsection{Smart Industry}

The development of industries depends on the support of information service, while the upgrade and reform of traditional industrial structure also depend on the construction and development of smart city. Becoming smart will bring a number of new industries, and provide the industrial structure of smart city development to transform smartly.

\subsubsection{Smart Traffic}

Smart traffic can provide diversified traffic information service to people, thus improving the running efficiency of urban traffic. While establishing a multi-functional traffic information service platform is an essential of smart traffic, which is also a necessity of smart city. With smart traffic applications such as traffic information detecting system and traffic navigating system, etc., intelligent analysis results of the system could be achieved from the urban traffic information, thus providing support to decision-making on urban traffic control and road condition optimization. Therefore, establishing a smart traffic function system is an urgent task at present.

\subsubsection{Smart Tour}

Accompanied with the development of smart city, various conveniences are needed for tour industry such as traffic navigation, shopping guide for tourists, restaurants and hotels, and scenic spots introduction. For achieving this goal, with the background of smart city construction, the tour industry is pacing towards network and smart direction, generating smart tour with informatization and digitization. This kind of all-around information service can build an integrated tour industry with smart chains containing various types of tours such as high-end forum tour, business exchange tour, scenery tour, delicious food oriented tour, shopping tour, etc. Therefore, establishing a smart tour function system is a necessity for promoting the city image.

\subsubsection{Smart Power Grid}

When realizing the power system applicable for different demands of the people, to meet diversified power demands of people, it is a must to improve the quality of power supply, and reduce the waste of power source, thus providing power service network based on demands and time segment. This requires smart reformation of the transit and charging for power sources in existing power grid completely using technologies of remote sensing, intelligent control, sensor, etc, to dispatch power resource to people in more reasonable, efficient, flexible and reliable way. Therefore, smart power grid is the only choice for achieving this goal. The construction of smart power grid will be an infrastructure which is used to assess the construction of smart city.

\subsubsection{Smart Logistics}

The response speed required by clients is the goal of logistics corporations. It is an inexorable trend that the logistics industry grows and becomes a comprehensive service to meet the diversified demands of the people. By the support of technologies such as global positioning, media network, wireless remote sensing, IoT, etc., the logistics industry is developing and pacing into smart industry. To sum up, the construction of smart logistics enables high-efficient vehicle scheduling, real-time tracing and positioning, to meet the different demands of different groups of people. Therefore, constructing smart logistics function system is an effective way to find "the $3^{\text {rd }}$ Profit Source".

\subsection{Smart Governmental Fairs}

\subsubsection{Smart Government}

Electronic governmental fairs service system is based on Internet to deal with business through governmental fairs center and comprehensive governmental fairs platform, thus to improve the management capacity and service efficiency of government agencies. The social comprehensive supervision platform is for monitoring all the aspects in the city, and enabling higher supervision capacity and service level which are required by the government agencies. Those are the results of smart government management and service which are derived from technique measures such as sensors network, IoT, and camera surveillance network, global positioning system, etc. Therefore, structuring a smart governmental fairs functions system is an effective way to form a service government.

\subsubsection{Smart Safety}

The protection and emergency treatment capacity of the public safety of the city can be improved with public safety surveillance and management network well spread in every corner of the city to ensure the safety of the city. The development of public safety of smart city should be fully integrated with sensor network, IoT, video surveillance network and GPS. This is an important function which should be achieved by information services of smart city as well. Therefore, it is very important to establish a smart safety functions system.

\subsubsection{Smart Environment}

City environment management should adopt a set of concepts which value development and protection both in aspects such as energy-saving, emission reduction, greening, sanitation, etc. The overall supervision and earlier alarm are extremely important to against the environmental pollution in the city, which can avoid the old development method "Treatment after Pollution". All these depend on the environmental construction of smart city, the harmonious and safe urban environment. Therefore, structuring environmental functions system of a smart city is the outgoing window of a city.

\subsubsection{Smart Command}

As the "Head" of a city, by uniformly invoking various resources in the city, the command center optimizes the treatments on according events, as well as trace, supervise and analyze every aspect of the city. All the parts in the city will be unified and coordinated by smart city, to form an optimized city entirety to intelligently make decisions on various emergencies, hence the command center of a city is formed, which will uniformly allocate and utilize various resources in the smart city. Therefore, itis necessary to structure a smart command function system. 


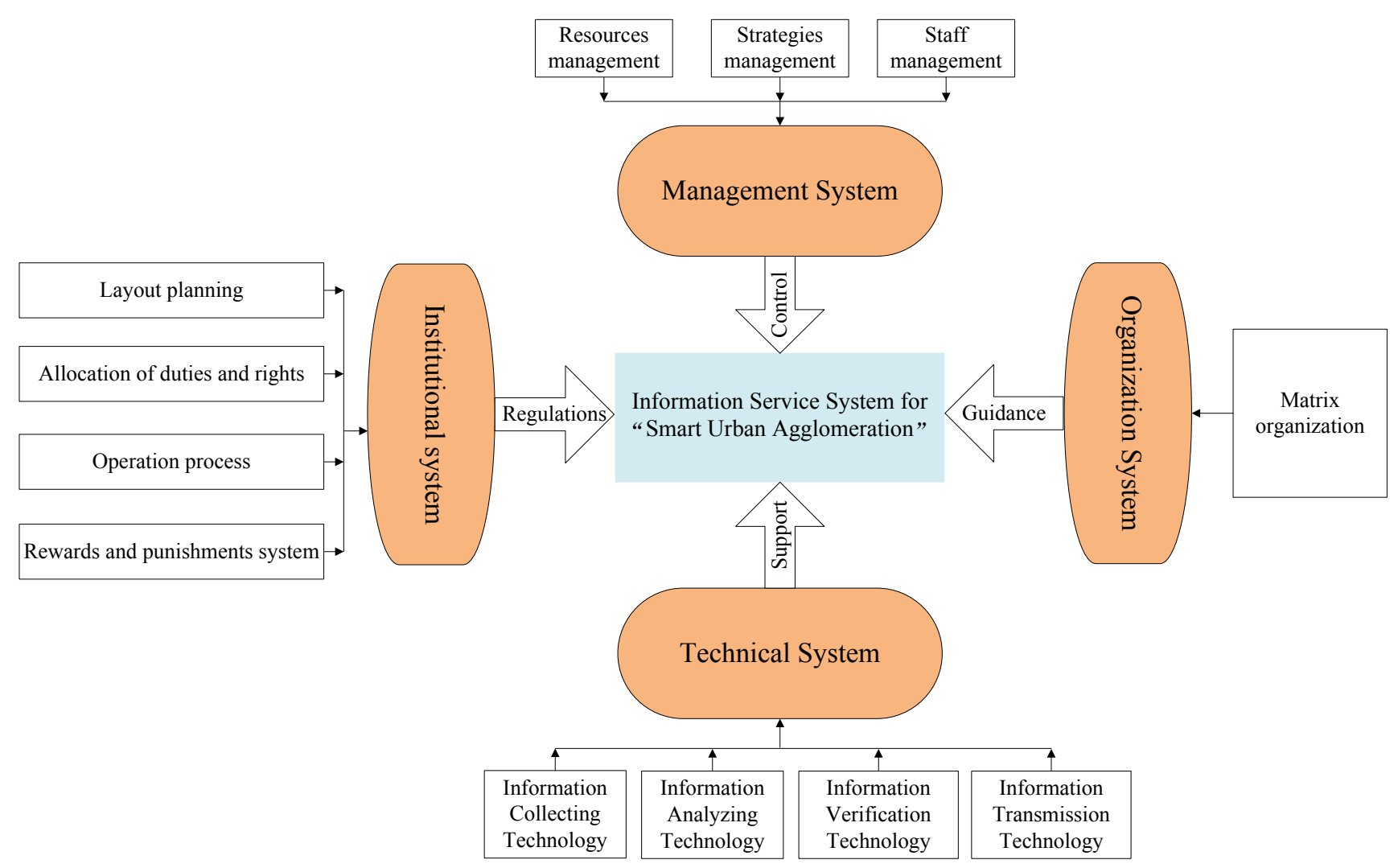

Fig. (9). System model of the information service of the "Smart Urban Agglomeration" of Changsha-Zhuzhou-Xiangtan".

\section{MODEL STRUCTURING OF INFORMATION SERVICE SYSTEM OF "SMART URBAN AGGLOM- ERATION" OF CHANGSHA-ZHUZHOU-XIANGTAN IN BIG DATA REQUIREMENTS}

With the support of big data technologies, and above designed information service functions for "Smart Urban Agglomeration" of Changsha-Zhuzhou-Xiangtan, as well as three principles organized by the government, guided by the system, and demand-oriented, this paper structures the four system factors, and establishes the overall model of information service system of "Smart Urban Agglomeration" of Changsha-Zhuzhou-Xiangtan. In this model, systems are implied in establishing detailed regulations for effectively controlling the services. The technical support for the services is relied on the deployment of technical system, which is the core of service system. The establishment of departments and allocation of duties are guided by organization system. Meanwhile, the overall control is subject to management system, the correct development direction and goals determined by the control service system. Given above are important considerations for the high efficiency of service system.

\subsection{System Standards of Information Service of A Smart City}

Information service of a smart city belongs to service industry. The businesses involved in it should have uniform and stable procedures. Therefore, there should be regulations and a system for the detailed business procedures, to ensure the quality of information service. Then, the information service of "Smart Urban Agglomeration" of ChangshaZhuzhou-Xiangtan must specifically identify the business contents with regulations and standard systems, to restrain the impact of human and practical factors on information service within a reasonable level, and ensure the stability and continuation of information service system. It is also a must to strengthen the government and standards system, as well as implement them step by step, and dynamically refine them, based on the development regulations required by the construction of "Smart Urban Agglomeration" of ChangshaZhuzhou-Xiangtan at the state, industrial and regional levels, which follow the international standards and regulations.

\subsection{Organizational System of Information Service of A Smart City}

In information service system of a smart city, one of the important components is organizational system, which is used to define the duties of each position, the structure of departments, and the allocation of duties and rights. During the construction of information service system for "Smart Urban Agglomeration" of Changsha-Zhuzhou-Xiangtan, itis mandatory to analyze carefully the characteristics of each business, and successfully implement and efficiently operate the information service system, provided that the orderly 
construction of "Smart Urban Agglomeration" of ChangshaZhuzhou-xiangtan is assured. Under the impact of outer social environment and inner business procedures, the detailed businesses of organization system are: 1) when the outer environment is changing rapidly, improving the adaption capability of the organization; 2) when the communication effect is not obvious, enhancing the coordination among departments; and 3) when the cost efficiency is low, sharing and optimizing the resources among departments.

\subsection{Technical System of Information Service of The Smart City}

One of the important aspects of the information service system in the "Smart Urban Agglomeration" of ChangshaZhuzhou-Xiangtan is the technical system. The completion and advancement of a technical system directly influence the overall quality and effect of the information service system. The technical system of the information service in the "Smart Urban Agglomeration" of Changsha-ZhuzhouXiangtan is mainly composed of technologies such as information collection and management, cloud computation, IoT, etc. The technical system of the "Smart Urban Agglomeration" of Changsha-Zhuzhu-Xiangtan should provide perceptive end and handling end for the information service, by collecting and managing information with the support of broadband communication fundamental network. On one hand, the technical system of the "Smart Urban Agglomeration" of Changsha-Zhuzhou-Xiangtan should provide applications integration for each IoT industry and big data analysis based on cloud. While, on another hand, it should lead all the industries to networked stage to enable comprehensive urban perception and grid control, thus to effectively ensure comprehensive extension and overall integration of the information service system of the "Smart Urban Agglomeration" of Changsha-Zhuzhou-Xiangtan.

\subsection{Management System of The Information Service of The Smart City}

The constructive quality and running effect of the information service system of the smart city are all determined by the management level and efficiency. Each task in the construction of quality and sufficient information service in Changsha, Zhuzhou and Xiangtan is relied on the reasonable goals of management system. For example: planning and revision of strategic goals; setting and deployment of resource goals; accuracy and allocation of information goals. They are all determined by the construction of management system, as well as the detailed practices during the operation of management system. Therefore, the system regulations of management system for the information service in the "Smart Urban Agglomeration" of Changsha-ZhuzhouXiangtan play a significant role in the construction and operation of the whole system Fig. (9).

5.5 The structural factors in the information service system of the smart city are not separated from but interact with each other; they are not isolated but connected, thus forming a smart overall structure of information service system. Based on the above summary, this paper structures the system models of the information services of the smart city, as well as the overall model of the information service system of the smart city [10].

\section{CONCLUSION}

Big data technologies are always the most fundamental and direct support for intelligent information service during the development of a city. Application and analysis with big data technologies are the detailed expressions of actual implementation of "Smart City". Under big data requirements, based on investigation and analysis, as well as functions design for the information service system of the "Smart Urban Agglomeration" of Changsha-Zhuzhou-Xiangtan, this paper focuses on model structuring for the information service system of the "Smart Urban Agglomeration" of ChangshaZhuzhou-Xiangtan, and offers some valuable suggestions to facilitate the construction and development of state level "Smart Urban Agglomeration", as well as the transformation and upgrading of information service industry.

\section{CONFLICT OF INTEREST}

The authors confirm that this article content has no conflict of interest.

\section{ACKNOWLEDGEMENTS}

This work is supported by the Key Project of Hunan province and consultation of decision problem, Research on Structuring of Information Service System "Smart Urban Agglomeration" of Changsha-Zhuzhou-Xiangtan, China (No.2014BZZ119).

\section{REFERENCES}

[1] Caragliu, C. Del Bo, and P. Nijkamp "Smart cities in Europe". Journal of Urban Technology, vol.18, no. 2, pp. 65-82, 2011.

[2] R.P. Dameri, "Searching for smart city definition: a comprehensive proposal". International Journal of Computers \& Technology, vol.11, no. 5, pp. 2544-2551, 2013.

[3] T. Nam, and T.A. Pardo "Conceptualizing smart city with dimensions of technology, people, and institutions". Proceedings of the 12th Annual International Conference on Digital Government Research, pp. 282-291, 2011.

[4] Kehua $\mathrm{Su}, \mathrm{J} \mathrm{Li}$, and $\mathrm{H}$. Fu "Smart city and the applications". IEEE International Conference on Electronics, Communications and Control (ICECC), pp. 1028-1031 2011.

[5] L. Batagan, "Smart cities and sustainability models", Informatica Economică, vol.15, no. 3, pp. 80-87, March 2011.

[6] Harrison, B. Eckman, R. Hamilton, P. Hartswick, J. Kalagnanam, J. Paraszczak, P. Williams, "Foundations for smarter cities", IBM Journal of Research and Development, vol.54, no. 4, pp.1-16, 2010.

[7] H. Schaffers, C. Ratti, and N. Komninos, "Special issue on smart applications for smart cities-new approaches to innovation", Journal of Theoretical and Applied Electronic Commerce Research, vol.7, no. 3, pp. 7-17, March 2012.

[8] T. Bakıcı, E. Almirall, and J. Wareham, "A Smart City initiative: The case of Barcelona". Journal of Knowledge Economy, vol.4, no. 2, pp.135-148, 2013. 
[9] J.H. Lee, R. Phaal, and S.H. Lee, "An integrated service-devicetechnology roadmap for smart city development". Technological Forecasting and Social Change, vol. 80, no. 2, pp. 286-306, 2013.
[10] S. Zygiaris, "Smart city reference model: assisting planners to conceptualize the building of smart city innovation ecosystems", Journal of the Knowledge Economy, vol. 4, no. 2, pp. 217-231, 2013.

Received: September 16, 2014

Revised: December 23, 2014

Accepted: December 31, 2014

(C) Xin Liu; Licensee Bentham Open.

This is an open access articles licensed under the terms of the Creative Commons Attribution-Non-Commercial 4.0 International Public License (CC BY-NC 4.0) (https://creativecommons.org/licenses/by-nc/4.0/legalcode), which permits unrestricted, non-commercial use, distribution and reproduction in any medium, provided that the work is properly cited. 